\title{
Article \\ The Effect of Current Supply Duration during Stepwise Electrical Sintering of Silver Nanoparticles
}

\author{
Iksang Lee ${ }^{1}$, Arif Hussain ${ }^{1}\left(\mathbb{D}\right.$, Hee-Lak Lee ${ }^{1}\left(\mathbb{D}\right.$, Yoon-Jae Moon ${ }^{1,2}$, Jun-Young Hwang ${ }^{2}$ \\ and Seung-Jae Moon $1, * \mathbb{D}$ \\ 1 Department of Mechanical Convergence Engineering, Hanyang University, Seoul 04763, Korea; \\ whisky330@naver.com (I.L.); enggaskari@gmail.com (A.H.); joylee1112@hanyang.ac.kr (H.-L.L.); \\ myj3235@kitech.re.kr (Y.-J.M.) \\ 2 Korea Institute of Industrial Technology, Ansan 15588, Korea; jyhwang@kitech.re.kr \\ * Correspondence: smoon@hanyang.ac.kr
}

Citation: Lee, I.; Hussain, A.; Lee, H.-L.; Moon, Y.-J.; Hwang, J.-Y.; Moon, S.-J. The Effect of Current Supply Duration during Stepwise Electrical Sintering of Silver Nanoparticles. Metals 2021, 11, 1878. https://doi.org/10.3390/ met11111878

Academic Editor: Eric Hug

Received: 4 October 2021

Accepted: 20 November 2021

Published: 22 November 2021

Publisher's Note: MDPI stays neutral with regard to jurisdictional claims in published maps and institutional affiliations.

Copyright: (c) 2021 by the authors. Licensee MDPI, Basel, Switzerland. This article is an open access article distributed under the terms and conditions of the Creative Commons Attribution (CC BY) license (https:// creativecommons.org/licenses/by/ $4.0 /)$.

\begin{abstract}
We studied the effect of current supply duration at final-step currents during the stepwise electrical sintering of silver (Ag) nanoparticles (NPs). Ag NPs ink was inkjet-printed onto Eagle-XG glass substrates. Constant final-step currents of 0.4 and $0.5 \mathrm{~A}$ with various time intervals were applied to the printed samples. The final-step current of $0.5 \mathrm{~A}$ damaged the line at a comparatively shorter time duration. On the other hand, the lower final-step current of 0.4 A prevented the line damage at longer time durations while producing comparatively lower Ag NPs specific resistance. The minimum specific resistances of the printed samples sintered at 0.4 and $0.5 \mathrm{~A}$ were $3.59 \mu \Omega \cdot \mathrm{cm}$ and $3.79 \mu \Omega \cdot \mathrm{cm}$, respectively. Furthermore, numerical temperature estimation and scanning electron microscope (SEM) analysis were conducted to elaborate on the results. The numerical temperature estimation results implied that the lower estimated peak temperature at the final-step current of 0.4 A helped prevent Ag NP line damage. The SEM micrographs suggested that a high surface porosity-caused by higher sintering peak temperatures-in the case of the $0.5 \mathrm{~A}$ final-step current resulted in a comparatively higher Ag NP line-specific resistance. This contribution is a step forward in the development of Ag NP sintering for printed electronics applications.
\end{abstract}

Keywords: stepwise current sintering; silver nanoparticle; specific resistance; neck growth; electrical sintering

\section{Introduction}

Printed electronics has attracted enormous attention as a promising alternative to conventional lithography. Among the several printing techniques [1-7], the inkjet printing technique has stood out as a promising alternative to overcome the complex processes of conventional lithography $[8,9]$. The inkjet printing technique is environmentally friendly as it uses the exact amount of required material by allowing a direct patterning on the substrate, hence preventing the use of chemicals etchants and the etching process entirely $[10,11]$. This technology has been widely applied to flexible displays [12], flexible solar cell arrays [13], and printed OFETs [14,15]. Highly conductive metal nanoparticle inks such as silver [12,16] or copper nanoparticles [17-20] are generally adopted for the contacts and tracks in electronic circuit design to minimize resistive losses. They are inkjet-printed onto different substrates for producing printed features for electronic devices [14,15]. However, metal nanoparticle inks generally have too low electrical conductivity to meet the general requirements due to the surfactants added in the ink to prevent agglomeration [9]. Therefore, once printed onto the substrate, the metal nanoparticle ink is heat-treated to render the printed features conductive. This impediment demands a further step called sintering, which is a thermal treatment for bonding particles together into a coherent, predominantly solid structure via mass transport events that occur largely at the atomic level [21]. Different techniques such as microwave oven [22,23], hotplate [24], laser [25,26], 
intense pulsed light (IPL) [27], and room temperature sintering [28] have been previously studied each with their specific characteristics and outcomes. While oven sintering is the conventional technique with the advantages of large area heat treatment and mass production, it has certain drawbacks such as (i) it requires longer processing time, (ii) causes thermal damage to the substrates, (iii) lacks selective sintering, and (iv) emits undesirable gases. As an alternative to oven sintering, Allen et al. [29] proposed an unconventional electrical sintering method by applying a constant voltage to the silver nanoparticle conductive ink line. In a later study, Moon et al. [30] demonstrated the constant current method during the electrical sintering of Ag NPs as an alternative to the constant voltage method. Furthermore, Alastalo et al. [31] introduced a numerical solution model related to the heat expansion of silver nanoparticles when printed and sintered on a paper substrate. Tan et al. [32] have presented contactless electrical sintering via induction heating with a staggering Ag NPs specific resistance of $1.98 \mu \Omega . \mathrm{cm}$. Hence, the studies demonstrated the electrical sintering method with several key advantages such as (i) highly localized sintering, (ii) short processing time, (iii) inducing minimal thermal damage to the substrate, and (iv) allowing the in situ monitoring of the sintering quality. Moreover, in the current study, we have demonstrated that the particular stepwise electrical sintering technique allows the control over the process temperature and subsequently the NP final resistivity.

During the electrical sintering, the current is applied at the ends of the conductive ink line. If the applied current is too high, the excessive thermal energy generated by Joule heating could damage the line. Jang et al. [33] proposed a two-step sintering method to prevent generating excessive thermal energy in the printed conductive ink by gradually increasing the applied voltage, rendering a stable reduction in the resistance of the sample. Lee et al. [34] proposed a stepwise current-increment sintering technique to prevent excessive thermal energy to the printed conductive ink due to high initial resistance. A gradual increase in the current in the form of steps prevents the supply of excess energy to the sample without damage. However, the current supply duration corresponding to the final-step current remains the topic of exploration.

In this work, the effects of the current supply duration at the final step were investigated during the stepwise electrical sintering of Ag NPs. During thermal sintering, the electrical specific resistance of metal NPs is highly dependent on the sintering temperatures. In a stepwise current increment electrical sintering technique, the maximum temperature occurs at the final step of the current supply. By varying the final-step current duration, the heating time and hence the maximum temperature can be controlled. This technique allows the control over sintering temperature, and hence, the final specific resistance of the Ag NPs such that it provides us with the choice of higher sintering temperatures and discontinuous surface morphology or lower sintering temperatures but smooth and continuous surface morphology. The effect of sintering temperatures has been studied by Moon et al. [35] in which a $300{ }^{\circ} \mathrm{C}$ oven sintering temperature produced lower specific resistivity compared to $250^{\circ} \mathrm{C}$ at the expense of highly discontinuous surface morphology containing large pores. However, at higher than $300^{\circ} \mathrm{C}$, the NP grain sizes became larger than the thickness of the NP film layer, forming islands. In this study, the relation between the temperature and electrical property change of the conductive ink line was examined by solving a two-dimensional conduction equation, and the surface morphology was carried out by analyzing the field emission scanning electron microscopt (FE-SEM) of the sintered NPs.

\section{Materials and Method}

Figure 1 shows the FE-SEM image of the conductive ink line printed on the glass substrate before sintering. Ag NPs ink (DGP 40LT-15C, ANP Inc., Sejong, Korea) with around $34 \mathrm{wt} \%$ solid content and an average particle size of about $50 \mathrm{~nm}$ uniformly dispersed in triethylene glycol monomethyl ether (TGME) solvent was used. Glass substrates (Eagle XG glasses, Samsung-Corning, Glendal, AZ, USA) were cleaned with acetone and isopropyl alcohol (IPA) in an ultrasonic cleaner for $10 \mathrm{~min}$ each, respectively. Afterward, the glass 
substrate was kept in an oven at $110{ }^{\circ} \mathrm{C}$ for $30 \mathrm{~min}$ to remove the residual moisture. Two identical pads $(1000 \mu \mathrm{m} \times 1000 \mu \mathrm{m})$ were printed on the glass substrate and baked in an oven at $250{ }^{\circ} \mathrm{C}$ for $30 \mathrm{~min}$ to reduce any error during the conductive line resistance measurement. Subsequently, Ag NP ink lines were printed by connecting the pads with $130 \mu \mathrm{m} \times 3000 \mu \mathrm{m}(\mathrm{W} \times \mathrm{L})$ dimensions. A pre-sintering process was carried out to obtain uniform initial resistances of $1165 \pm 88 \Omega$ for each Ag NP line sample. This process removed the printed ink moisture, leaving dry NP lines. The SEM (Hitachi S-4800, Hitachi High-Tech. Co., Tokyo, Japan) image in Figure 1 depicts the adhering of NPs before the initial point contact of the NPs where the initial point contact of the NPs indicates the initiation of sintering [21]. Therefore, at this point, considering the high resistance and mere adherence of the NPs, it is safe to say that the sintering process has not started. The pre-sintering process was carried out by heating the printed samples on a hotplate at $55^{\circ} \mathrm{C}$ for $300 \mathrm{~s}$.

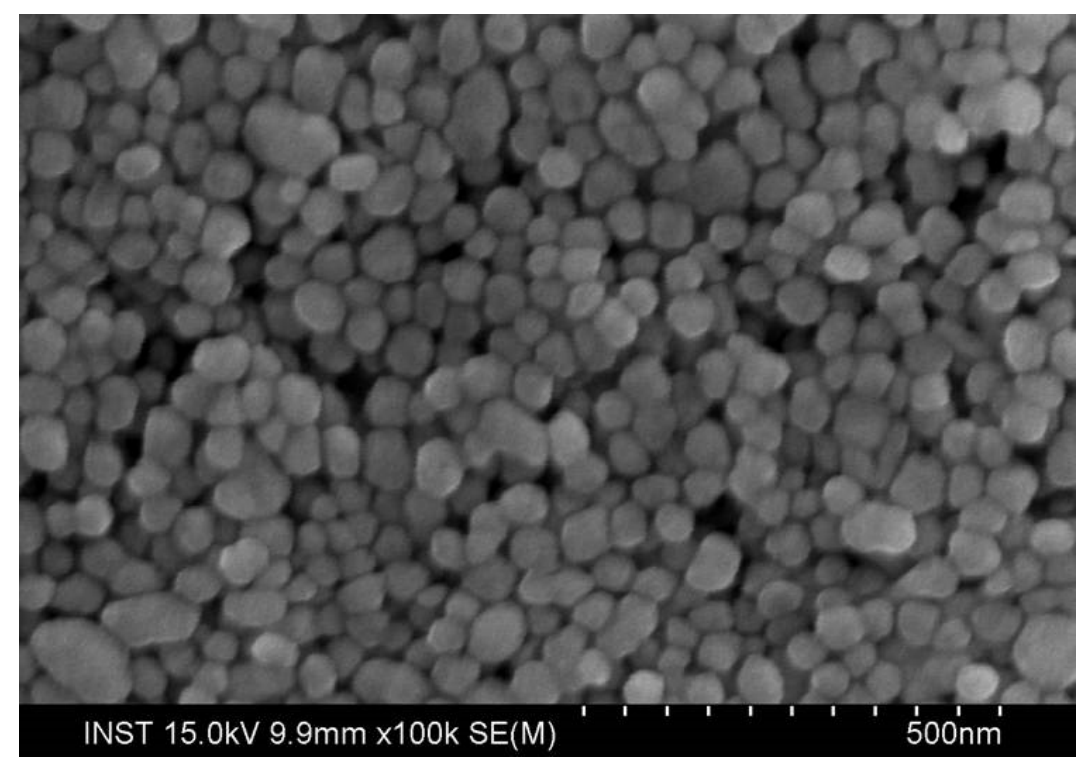

Figure 1. Field emission scanning electron microscope (FE-SEM) image of silver nanoparticles before sintering.

Figure 2 illustrates the schematic diagram of the electrical circuit. The electrical sintering was performed via a stepwise-current form generated from a computer-controlled DC power supply. Sintering was carried out in four steps in each experiment. The current was increased at each step corresponding to time variations (200 to $5150 \mathrm{~ms}$ ) up to finalstep currents of $0.4 \mathrm{~A}$ and $0.5 \mathrm{~A}$. Furthermore, to measure the supplied current, the series resistor $(1 \Omega)$ was connected to the electrical circuit. The transientvoltage of the sample was determined using an oscilloscope by connecting probes at both ends of the sample. After the sintering process, the final resistance of the sintered samples was determined at room temperature using a digital multimeter (L4411A, Agilent Technologies, Santa Clara, CA, USA), and the specific resistance of the samples was calculated by Ohm's Law. The equation of the average specific resistance is as follows:

$$
\rho=R \frac{A}{L},
$$

where $\rho, R, A$, and $L$ are the specific resistance, line resistance, cross-sectional area, and length of the conductive line, respectively. The surface morphology of the sintered conductive ink line was monitored by FE-SEM (Hitachi S-4800 Hitachi High-Tech. Co., Tokyo, Japan). The line resistance was measured in situ via the digital multimeter during the electrical sintering process. 


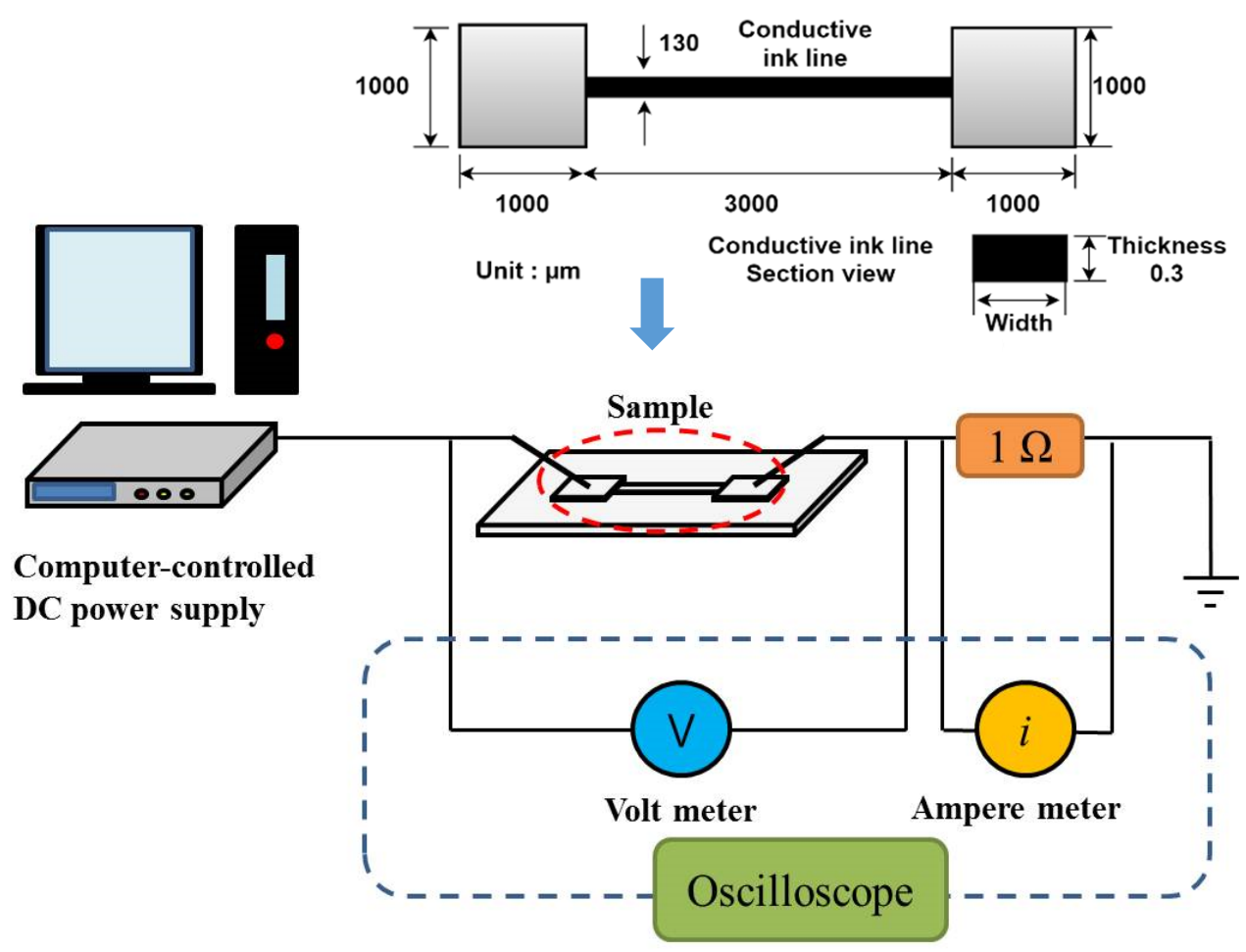

Figure 2. Schematics of the stepwise current sintering setup.

The temperature calculation was carried out by solving a two-dimensional heat conduction equation using the COMSOL Multiphysics (COMSOL, Inc., District Avenue Burlington, MA, USA). The Wiedemann-Franz law was used to estimate the transient thermal conductivity of the Ag NP ink, which states that "The ratio of the thermal conductivity to the electrical conductivity of metal at not too low temperatures is directly proportional to the temperature [36]," and it is expressed as follows:

$$
k=L_{\text {silver }} \cdot \sigma(t) \cdot T,
$$

where $k, \sigma(t)$, and $T$ are the thermal conductivity, electrical conductivity of silver nanoparticles, and temperature, respectively. The Lorentz number of silver, $L_{\text {silver }}$, is $2.44 \times 10^{-8}$ [36]. The electrical conductivity is the reciprocal of the specific resistance. We obtained the electrical conductivity by the in situ measurement of line resistance, and subsequently, the thermal conductivity via Equation (2). When comparing Equations (1) and (2), we observe that the information regarding the change in the NP cross-sectional area is required in the numerical model for estimating the thermal conductivity-dependent temperature. However, since the area shrinkage when the NPs are thermally treated for short times is negligible based on the previous study by oven sintering [37], therefore considering a fraction of time taken during the electrical sintering compared to oven sintering, we assumed that the area shrinkage remained constant throughout the sintering process. The two-dimensional heat conduction equation is as follows:

$$
\begin{gathered}
\rho_{i} c_{p, i} \frac{\partial T_{i}}{\partial t}=\frac{\partial}{\partial x}\left(k_{i} \frac{\partial T_{i}}{\partial x}\right)+\frac{\partial}{\partial y}\left(k_{i} \frac{\partial T_{i}}{\partial y}\right)+S_{i}, i=1,2 \\
S_{i}=I^{2}\left(\frac{\rho_{e 1} l_{1}}{A_{1}}\right), S_{2}=0
\end{gathered}
$$

where $\rho_{i}, c_{p, i}$, and $k_{i}$ are the density, heat capacity, and thermal conductivity of Ag NPs and the glass substrate, respectively. The subscript $i$ is the representation for each material: 
1 for ink and 2 for the glass substrate. $\rho_{e}, I, A_{1}$, and $l_{1}$ are the resistivity, applied current, cross-sectional area, and the length of the conductive ink line.

Figure 3 shows the schematics of the two-dimensional model of the Ag NPs ink line printed on the glass substrate. The radiative and convective boundary conditions were applied to the ink and the surface of the glass substrate. Both sides of the glass substrate were subjected to an adiabatic condition by assuming symmetry. An interface boundary condition was applied at the boundary between conductive ink and substrate. The initial temperatures of the ink and glass substrates were $300 \mathrm{~K}$. The parameters used in temperature calculation are shown in Table 1. For ink and glass substrate meshes, 53,122 elements were adopted, respectively. The average mesh quality was 0.843 with 1 as the best possible mesh quality.

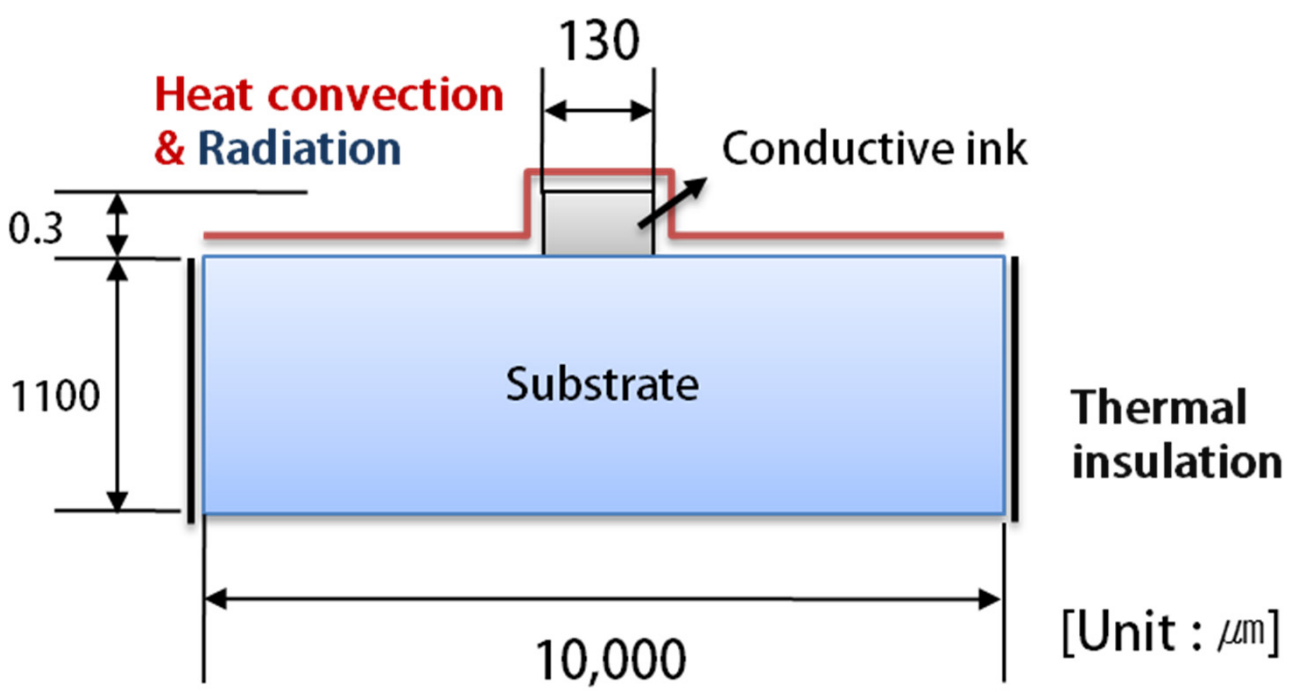

Figure 3. Two-dimensional numerical model of the patterned conductive ink line on the glass substrate.

Table 1. Parametric values used in the numerical calculation model.

\begin{tabular}{|c|c|c|c|c|c|}
\hline $\begin{array}{c}\text { Parameters } \\
\text { (Silver NP Ink) }\end{array}$ & Symbol & Values & $\begin{array}{c}\text { Parameters } \\
\text { (Glass Substrate) }\end{array}$ & Symbol & Values \\
\hline Density & $\rho_{1}$ & $5400 \mathrm{~kg} / \mathrm{m}^{3}$ & Density & $\rho_{2}$ & $2600 \mathrm{~kg} / \mathrm{m}^{3}$ \\
\hline Emissivity & $\varepsilon_{1}$ & $0.01-0.02$ & Emissivity & $\varepsilon_{2}$ & 0.92 \\
\hline Heat Capacity & $c_{p, 1}$ & $245 \mathrm{~J} / \mathrm{kg} \cdot \mathrm{K}$ & Heat Capacity & $c_{p, 2}$ & $840 \mathrm{~J} / \mathrm{kg} \cdot \mathrm{K}$ \\
\hline $\begin{array}{l}\text { Convective Heat } \\
\text { Transfer Coefficient }\end{array}$ & $h$ & $10 \mathrm{~W} / \mathrm{m}^{2} \cdot \mathrm{K}$ & $\begin{array}{c}\text { Stephan-Boltzmann } \\
\text { Constant }\end{array}$ & $\sigma$ & $\begin{array}{l}5.67 \times 10^{-8} \\
\mathrm{~W} / \mathrm{m}^{2} \mathrm{~K}^{4}\end{array}$ \\
\hline Thermal Conductivity & $k_{1}$ & Equation (2) & Thermal Conductivity & $k_{2}$ & $1.05 \mathrm{~W} / \mathrm{m} \cdot \mathrm{K}$ \\
\hline Width & $w_{1}$ & $130 \mu \mathrm{m}$ & Width & $w_{2}$ & $2.4 \mathrm{~cm}$ \\
\hline Thickness & $t_{1}$ & $300 \mathrm{~nm}$ & Thickness & $t_{2}$ & $0.5 \mathrm{~cm}$ \\
\hline
\end{tabular}

\section{Results and Discussion}

Figure 4 shows the current versus time chart for each final-step current of $0.4 \mathrm{~A} \mathrm{(a)} \mathrm{and}$ $0.5 \mathrm{~A}(\mathrm{~b})$. The case of the final-step current of $0.4 \mathrm{~A}$ was tested for a total sintering duration of 200, 250,650, 1150, 2150, and $5150 \mathrm{~ms}$, with which the initial three steps were completed within $150 \mathrm{~ms}$. So, the final-step current of $0.4 \mathrm{~A}$ applied to each case for durations of 50 , $100,500,1000,2000$, and $5000 \mathrm{~ms}$. Similarly, in the second case, the final-step current of 0.5 A was applied to the Ag NP lines for 50, 100, 500, 1000, 2000, and $2850 \mathrm{~ms}$. The NP line was damaged when $0.5 \mathrm{~A}$ was applied for $2850 \mathrm{~ms}$. This line damage is depicted by the sharp decrease in the current at around $3 \mathrm{~s}$ of the final-step current of $0.5 \mathrm{~A}$. 


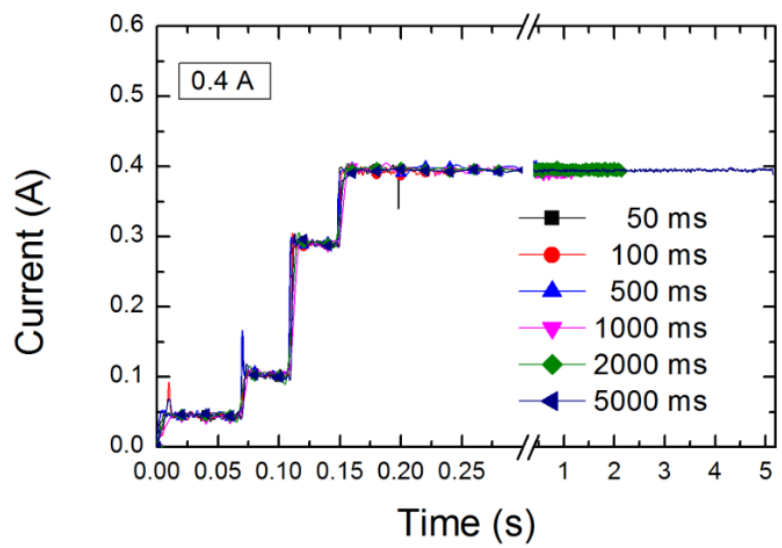

(a)

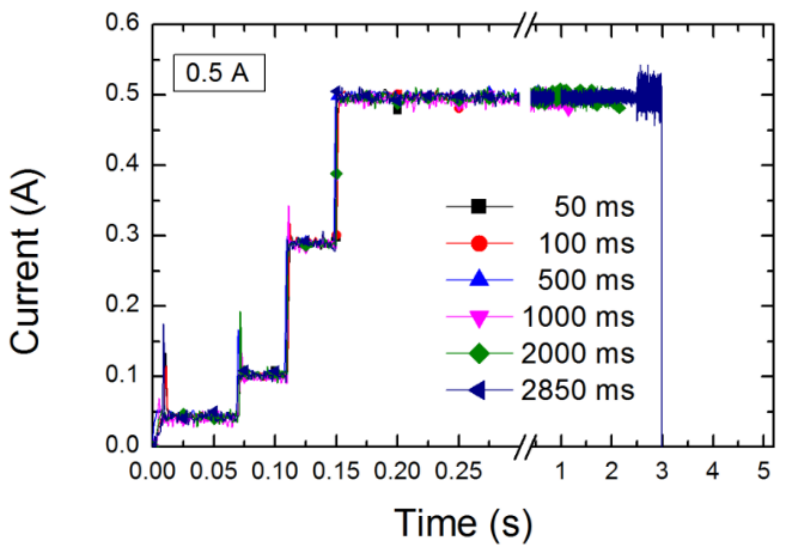

(b)

Figure 4. Stepwise current supply versus time plot with (a) the $0.4 \mathrm{~A}$ final-step current and (b) the $0.5 \mathrm{~A}$ final-step current.

Figure 5 presents the specific resistance curves of the final-step currents with $0.4 \mathrm{~A}$ and $0.5 \mathrm{~A}$ according to various final-step current supply durations. The specific resistance was measured at room temperature after sintering. The specific resistance decreased with the increased current supply duration at the final step. At the same time, the decrease rate slowed down as the final step duration was reduced. When the conductive ink lines were exposed to the final-step currents of $0.4 \mathrm{~A}$ and $0.5 \mathrm{~A}$ for $50 \mathrm{~ms}$ duration, the obtained specific resistances were 6.22 and $7.87 \mu \Omega \cdot \mathrm{cm}$, respectively. They were about 4.94 and 3.9 times the specific resistance of bulk silver $(1.59 \mu \Omega \cdot \mathrm{cm})$. The minimum specific resistance of the $0.5 \mathrm{~A}$ case occurred at the sintering time of $2150 \mathrm{~ms}$ when the final-step current of 0.5 A was applied for $2000 \mathrm{~ms}$. After 0.5 A current was supplied for $2850 \mathrm{~ms}$, the conductive lines were damaged due to the excessive temperature rise. However, the conductive lines were successfully sintered with a supply of $0.4 \mathrm{~A}$ current for $5000 \mathrm{~ms}$. The minimum specific resistances of the conductive ink lines sintered at $0.4 \mathrm{~A}$ for $5000 \mathrm{~ms}$ was $3.59 \mu \Omega \cdot \mathrm{cm}$, and the minimum specific resistance was $3.79 \mu \Omega$. when the conductive ink line was treated with $0.5 \mathrm{~A}$ for $2000 \mathrm{~ms}$. They were approximately 2.25 and 2.38 times that of bulk Ag. When the conductive lines were sintered for the identical final-step current supply duration, the lower specific resistance trend appeared with a $0.5 \mathrm{~A}$ current supply. However, the failure of a 0.5 A current supply at a longer sintering duration can be a major drawback, while the better line specific resistance is hard to obtain at shorter time durations with a supply of 0.5 A current. Therefore, the supply of a 0.4 A current for longer durations may be effective to produce comparatively lower specific resistance of the printed lines.

Figure 6 presents the surface morphology of the sintered Ag NPs with final-step currents of $0.4 \mathrm{~A}$. The FE-SEM images are shown for the various final-step duration. Typically, printed nanoparticle inks experience three different stages in the sintering process. At the very beginning, in the pre-sintering stage, the surfactants enclosing the NPs are evaporated by the supplied heat. Those surfactants prevent metal NPs from clogging inside inkjet printer nozzles during the ejaculation of the metal NP droplets. Next, once the surfactants are removed, the metal NPs start to agglomerate by adhering to each other and with the supply of small amount of thermal energy they start forming initial inter-particle necks. This stage is known to be the initial sintering stage [21]. The particles tend to attach randomly by activated repacking and rearrangement through the point contact of the particles. This point contact, consequently, initiates neck growth, which results in higher packing density and grain boundary structure with minimized surface energy. This process is possible by surface diffusion, which makes vacancies and atoms inside grains migrate along particle surfaces [21]. Figure $6 \mathrm{a}, \mathrm{b}$ shows the initially agglomerated structure when sintered with the final-step current of $0.4 \mathrm{~A}$ for $50 \mathrm{~ms}$ and $100 \mathrm{~ms}$, respectively. In the intermediate stage, nanoparticles are densified and grain growth is initiated simultaneously, as shown in Figure $6 c$,d. At this stage with a longer sintering duration, the necking between 
particles forms by surface diffusion with little actual densification [38]. Furthermore, when the lines are heated for $1000 \mathrm{~ms}$ duration, further growth in the neck is distinguished. This is caused by the grain boundary diffusion and the neck growth enhancement [25]. In Figure $6 c, d$, the densification of the particles starts [39] with the increased grain growth, and eventually, less grain boundary area is occupied. In the final stage, the grain growth results in the larger average grain size with a fewer number of grains [21], as revealed in Figure 6e,f with a final time duration of $2000 \mathrm{~ms}$ and $5000 \mathrm{~ms}$, respectively. Here, grain size enlargement initiates by atomic level diffusion within the crystal lattice. This process is known to be time-consuming and occurs after the proper densification of the microstructure $[21,38]$. This time-consuming diffusion explains the growth of larger grain size, as shown in Figure 6f. Moreover, we notice a noticeable large pore formation at $5000 \mathrm{~ms}$ with large grains and visible grain boundaries indicating that further current supply is likely to form islands and damage the NP line [35].

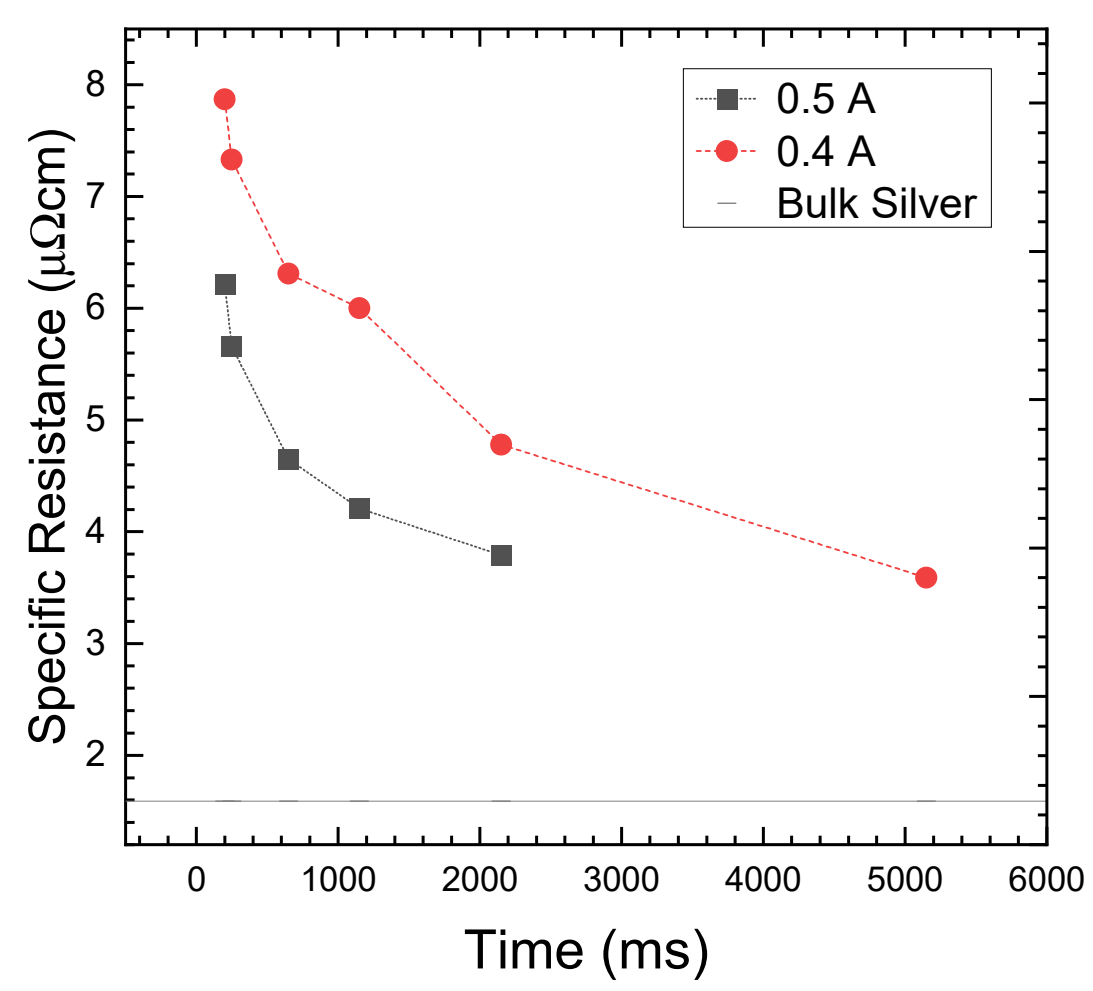

Figure 5. Specific resistance vs. time plot for $0.5 \mathrm{~A}$ and $0.4 \mathrm{~A}$ final-step currents.

Figure 7 shows FE-SEM images of the samples sintered with a final-step current of $0.5 \mathrm{~A}$. As the final step time increases, the supplied heating energy is increased, and a faster neck formation can be noticed, as shown in Figure 7a-c. After being heated with the final step duration of $1000 \mathrm{~ms}$, grains started to grow to a much larger size, which ranges from approximately 600 to $1000 \mathrm{~nm}$, as presented in Figure $7 \mathrm{~d}$. When the final step duration reaches $2000 \mathrm{~ms}$, the average grain sizes range from 0.5 to $1.5 \mu \mathrm{m}$ as shown in Figure 7e. When the final step duration increased to $2850 \mathrm{~ms}$, the samples were finally damaged with a grain size of around $\approx 1.7 \mu \mathrm{m}$. However, large pore formation will affect the final specific resistance of the conductive ink line, as shown in the 10,000x FE-SEM image in Figure 7g-i. The pore formation in the sintered samples effectively prevents the reduction of Ag NPs specific resistance close to its bulk counterpart's specific resistance. Hence, from the SEM micrographs, it is evident that the increase in the final step duration beyond a certain level consequently increased the size and the number of pores as well as the size of the grains and grain boundaries, resulting in an overall discontinuous surface morphology.

Figure 8 presents the calculated maximum temperature according to the varied finalstep durations with a final-step current supply of $0.4 \mathrm{~A}$ and $0.5 \mathrm{~A}$. The sintering temperature 
is known to affect the atomic diffusion mass flux and solvent removal among the nanoparticles [40]. The agglomeration of the nanoparticles is enhanced, since the increased sintering temperature leads to an accelerated redistribution of atoms and molecules among the nanoparticles [41]. The calculated temperatures are elevated with the increasing current supply duration, and the temperature slope is steeper at a final-step current of $0.5 \mathrm{~A}$. When the samples are sintered at the final-step current of 0.4 and $0.5 \mathrm{~A}$ for $50 \mathrm{~ms}$, the temperatures of the samples were 559 and $646 \mathrm{~K}$, respectively. When the samples were heated with $0.4 \mathrm{~A}$ for $5000 \mathrm{~ms}$ and $0.5 \mathrm{~A}$ for $2000 \mathrm{~ms}$, the estimated temperatures were 841 and $960 \mathrm{~K}$, respectively. The temperature of the damaged line was $1223 \mathrm{~K}$ with a final-step current of $0.5 \mathrm{~A}$ for $2850 \mathrm{~ms}$. This temperature is close to the melting temperature of bulk Ag $(1234.93 \mathrm{~K})$. The high estimated temperature indicates that the line was damaged due to layer discontinuity at the macro level caused by overheating.

Figure 9 reveals the relationship between the specific resistance of the conductive ink line and the corresponding estimated temperature. The temperature increase can be noticed with the increase in the final step time and applied currents. At around 800-850 K, a steep decrease in the specific resistance for $0.4 \mathrm{~A}$ indicates the formation of a better percolation network at this stage. The minimum specific resistance of the sample sintered with a final current of $0.4 \mathrm{~A}$ for $5000 \mathrm{~ms}$ was $3.59 \mu \Omega \cdot \mathrm{cm}$ at the temperature of $850 \mathrm{~K}$. At temperatures higher than $850 \mathrm{~K}$ in the case of $0.5 \mathrm{~A}$, the decrease rate of specific resistance according to temperature is slowed down. The slowing down of decrease rate is not as significant as in Figure 5 because the increase rate of temperature has also slowed down in these cases, as shown in Figure 8. In other words, at temperatures higher than $850 \mathrm{~K}$, the specific resistance decrease and temperature increase are both slowed down. The reason behind this phenomenon can be similar to the cause of damaged lines, where lines were damaged due to the discontinuity caused by overheating. We believe that the common features of large pores as observed in Figure $7 \mathrm{~g}-\mathrm{i}$ are the indication of a common cause. Higher porosity resulted in a comparatively higher final specific resistance of the NPs lines with $0.5 \mathrm{~A}$. An increase in the final-step current duration produced a better specific resistivity than the increase in the current at the final step. The steady temperature caused by the supply of the lower final-step current enabled a larger energy supply to the lines to obtain lower specific resistivity of the sintered lines by producing fewer pores in the sintered NPs morphology.

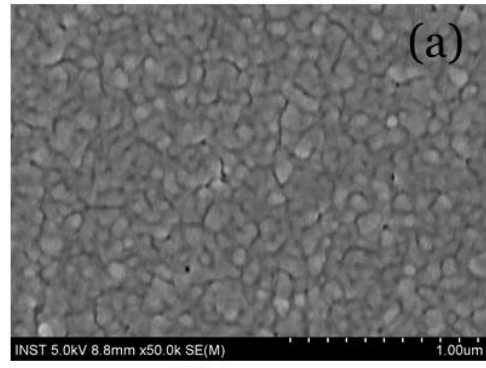

$50 \mathrm{~ms}$

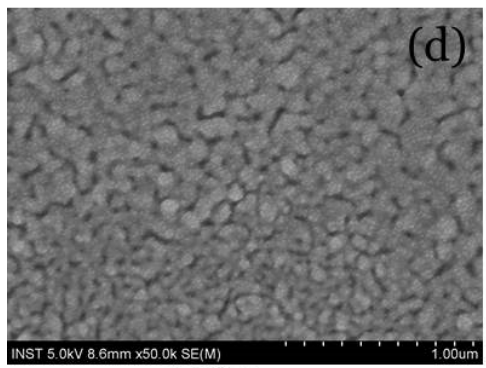

$1000 \mathrm{~ms}$

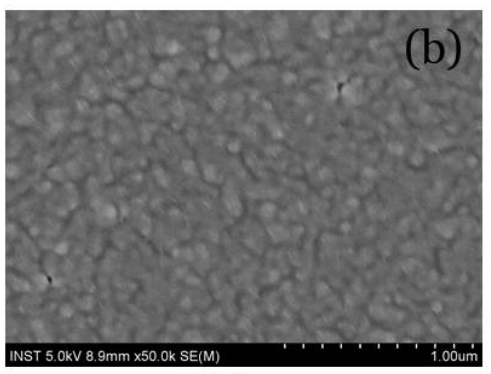

$100 \mathrm{~ms}$

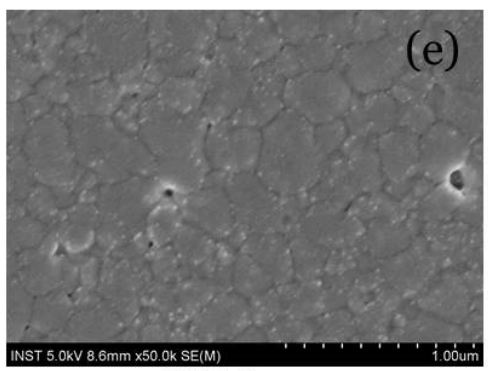

$2000 \mathrm{~ms}$

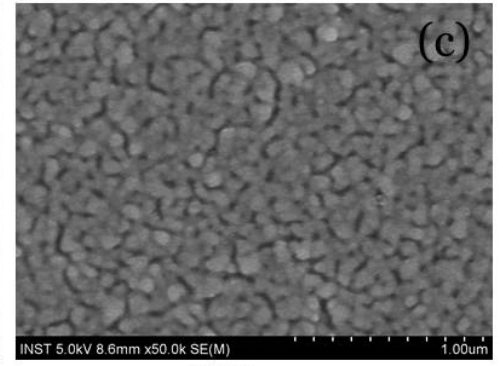

$500 \mathrm{~ms}$

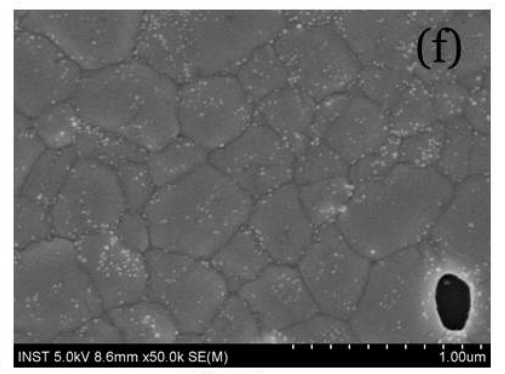

$5000 \mathrm{~ms}$

Figure 6. FE-SEM images of inkjet-printed silver nanoparticles sintered at a final-step current of $0.4 \mathrm{~A}$ at time durations of (a) $50 \mathrm{~ms}$, (b) $100 \mathrm{~ms}$, (c) $500 \mathrm{~ms}$, (d) $1000 \mathrm{~ms}$, (e) $2000 \mathrm{~ms}$, and (f) $5000 \mathrm{~ms}$, respectively. 


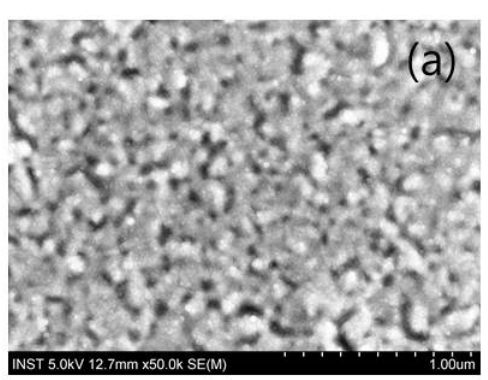

$50 \mathrm{~ms}$
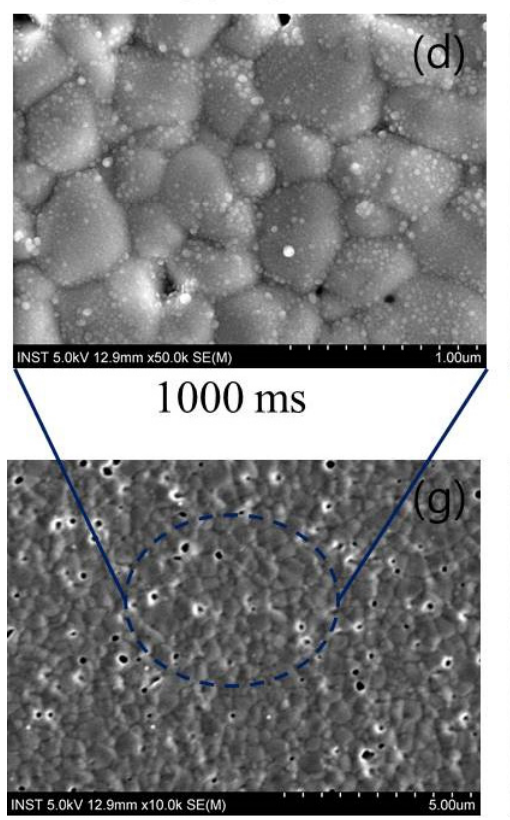

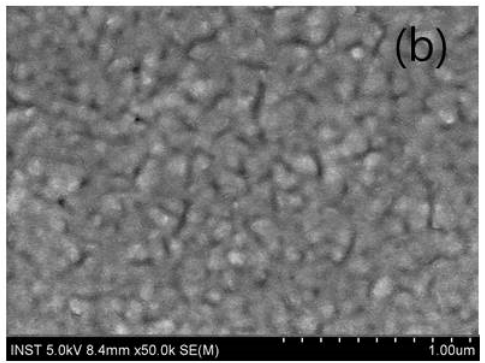

$100 \mathrm{~ms}$
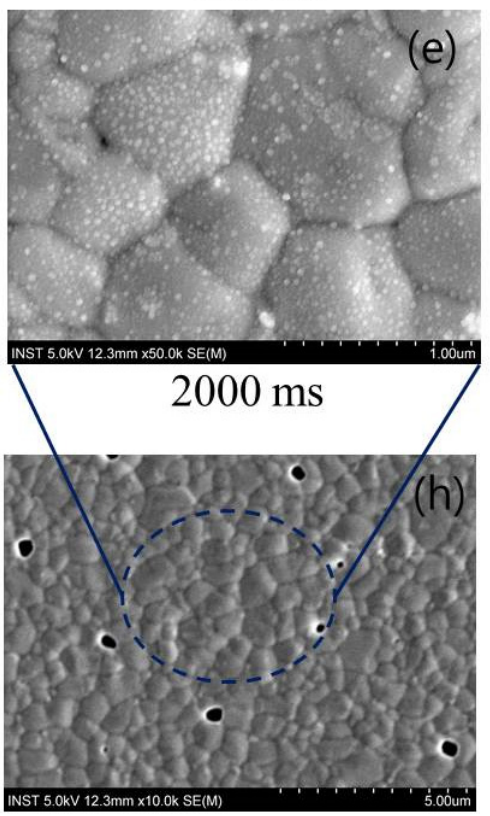

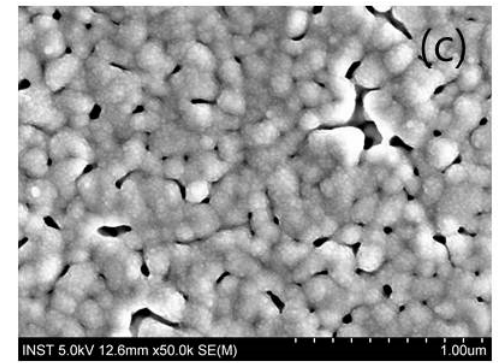

$500 \mathrm{~ms}$

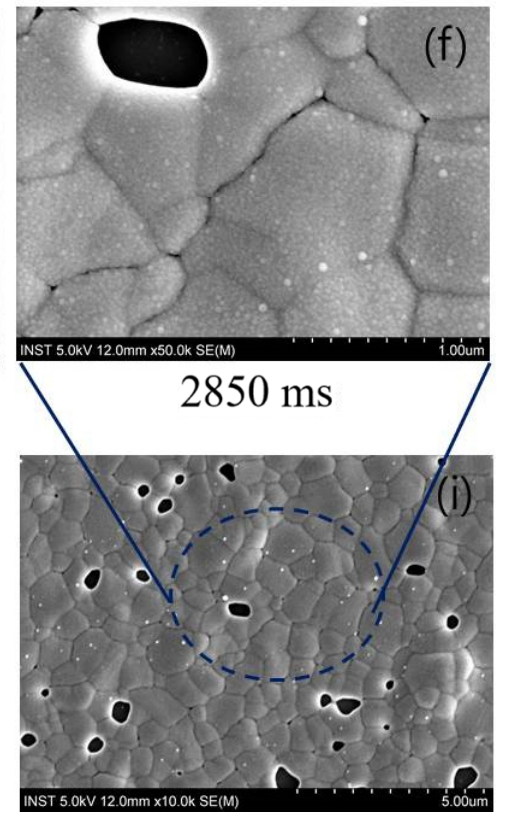

Figure 7. FE-SEM images of inkjet-printed silver nanoparticles sintered at the final-step current of $0.5 \mathrm{~A}$ at time durations of (a) $50 \mathrm{~ms}$, (b) $100 \mathrm{~ms}$, (c) $500 \mathrm{~ms}$, (d) $1000 \mathrm{~ms}$, (e) $2000 \mathrm{~ms}$, and (f) $2850 \mathrm{~ms}$, respectively. The images at the middle reveal $10,000 \times$ SEM images measured after sintering at final-step currents for 1150, 2150, and $2850 \mathrm{~ms}$, respectively (g-i).

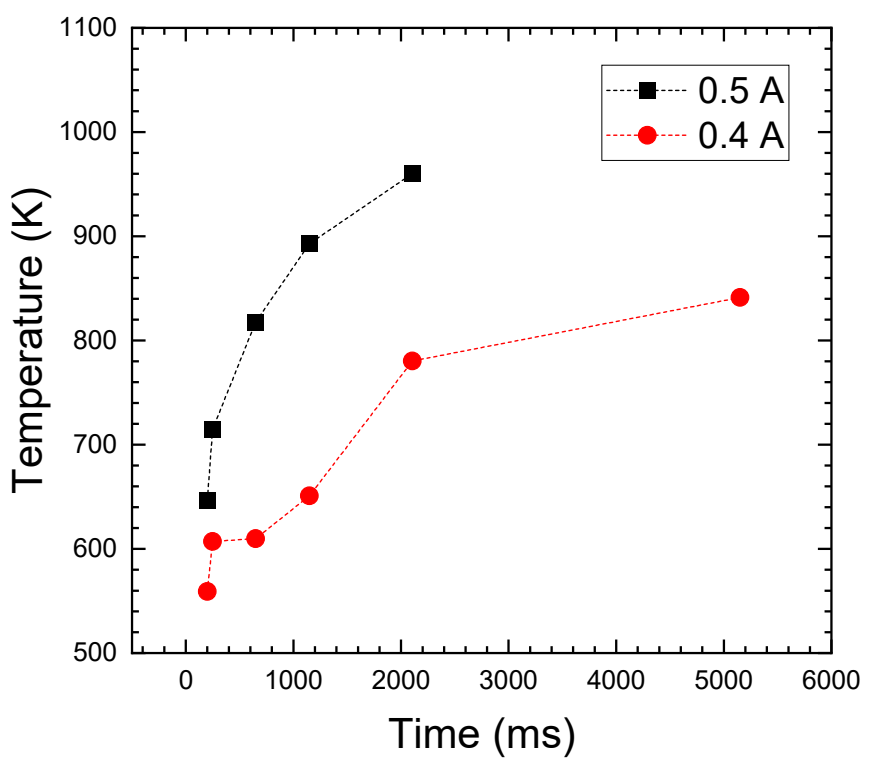

Figure 8. Estimation of temperature during the electrical sintering of silver nanoparticle ink according to $0.5 \mathrm{~A}$ and $0.4 \mathrm{~A}$, final-step currents. 


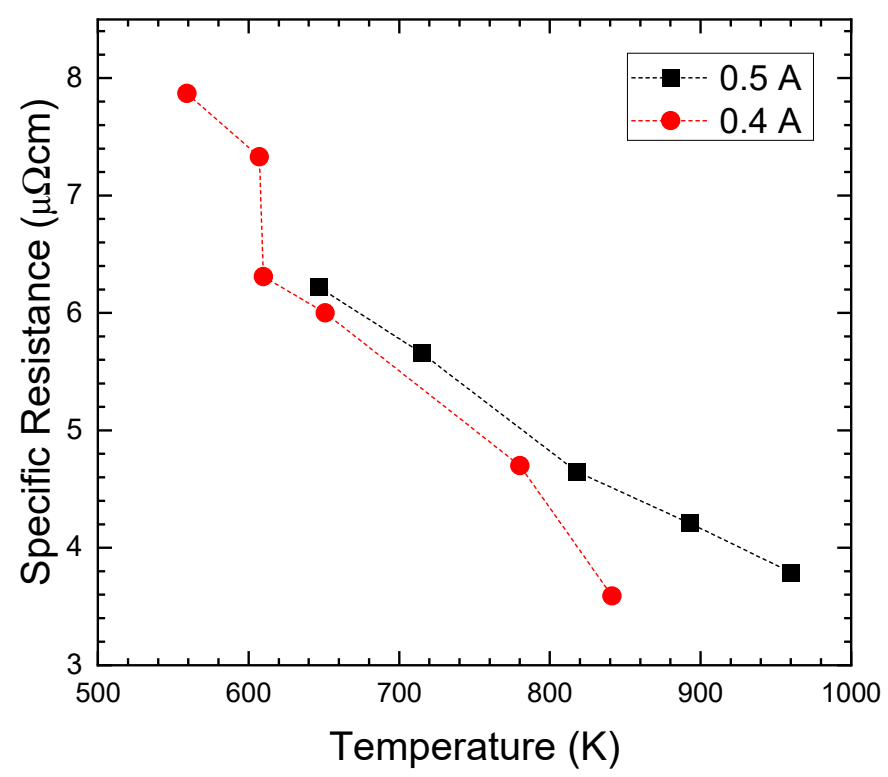

Figure 9. Relation between specific resistance of the silver nanoparticle ink and temperature with $0.5 \mathrm{~A}$ and $0.4 \mathrm{~A}$, final-step currents.

\section{Conclusions}

In this study, the effect of current supply duration during the electrical sintering of printed silver nanoparticle lines was investigated. We demonstrated that by controlling the current supply duration, the sintering temperatures can be manipulated. As a result, the final specific resistance of the printed Ag NPs lines can be obtained as desired until the lines are damaged. Moreover, this technique allows us to choose between a smoother surface morphology and a comparatively higher specific resistivity or discontinuous surface morphology and lower specific resistance, which is also one of the advantages of the conventional oven sintering. Between the $0.4 \mathrm{~A}$ and $0.5 \mathrm{~A}$ final-step currents, the $0.4 \mathrm{~A}$ finalstep current allowed the NPs sintering for $5000 \mathrm{~ms}$ inducing a comparatively lower specific resistance of $3.59 \mu \Omega \cdot \mathrm{cm}$, which is 2.25 times the bulk Ag specific resistance. On the other hand, the 0.5 A current damaged the NP line at $2850 \mathrm{~ms}$. Additionally, the numerically estimated temperatures and the FE-SEM micrographs suggested that the lower current with longer sintering durations produced comparatively continuous surface morphology. Meanwhile, the higher current produced highly porous structures at much shorter sintering durations with higher temperatures. We believe our contribution to the study of electrical sintering can be a step forward in the development of effective sintering techniques for electronics applications.

Author Contributions: Conceptualization, S.-J.M. and I.L.; methodology, Y.-J.M.; software, H.-L.L.; validation, Y.-J.M., A.H. and J.-Y.H.; formal analysis, I.L.; investigation, Y.-J.M.; resources, J.-Y.H.; data curation, A.H.; writing —original draft preparation, I.L.; writing—review and editing, S.J.M.; supervision, S.-J.M.; project administration, S.-J.M.; funding acquisition, J.-Y.H. All authors have read and agreed to the published version of the manuscript.

Funding: This study was conducted with the support of the Korea Institute of Industrial Technology as "Development of root technology for multi-product flexible production" (KITECH EO-21-0008).

Institutional Review Board Statement: Not applicable.

Informed Consent Statement: Not applicable.

Data Availability Statement: Not applicable.

Conflicts of Interest: The authors declare no conflict of interest. The funders had no role in the design of the study; in the collection, analyses, or interpretation of data; in the writing of the manuscript, or in the decision to publish the results. 


\section{References}

1. Zschieschang, U.; Klauk, H.; Halik, M.; Schmid, G.; Dehm, C. Flexible organic circuits with printed gate electrodes. Adv. Mater. 2003, 15, 1147-1151. [CrossRef]

2. Miller, M.S.; Davidson, G.J.E.; Sahli, B.J.; Mailloux, C.M.; Carmichael, T.B. Fabrication of elastomeric wires by selective electroless metallization of poly(dimethylsiloxane). Adv. Mater. 2008, 20, 59-64. [CrossRef]

3. Makrygianni, M.; Kalpyris, I.; Boutopoulos, C.; Zergioti, I. Laser induced forward transfer of Ag nanoparticles ink deposition and characterization. Appl. Surf. Sci. 2014, 297, 40-44. [CrossRef]

4. Liu, Q.; Xu, B.; Zhang, Y.; Wang, X.; Mei, X.; Wang, X. Picosecond laser sintering of silver paste printed by laser induced forward transfer. Opt. Laser Technol. 2021, 135, 106712. [CrossRef]

5. Kim, S.; Lee, W.S.; Lee, J.; Park, I. Direct micro/nano metal patterning based on two-step transfer printing of ionic metal nano-ink. Nanotechnology 2012, 23, 285301. [CrossRef] [PubMed]

6. Dziedzic, A.; Słobodzian, P. Modern microelectronic technologies in fabrication of RFID tags. Radioengineering 2011, $20,21-187$.

7. Dziedzic, A. Thick film resistors with $\mathrm{IrO} 2$ and Calr $\times$ Ti1-xO3-examples of chemically reactive and unreactive systems. Microelectron. J. 1988, 20, 187-193. [CrossRef]

8. Lee, H.H.; Chou, K.-S.; Huang, K.C. Inkjet printing of nanosized silver colloids. Nanotechnology 2005, 16, 2436-2440. [CrossRef]

9. Rogers, J.A.; Paul, K.E.; Jackman, R.J.; Whitesides, G.M. Using an elastomeric phase mask for sub-100 nm photolithography in the optical near field. Appl. Phys. Lett. 1997, 70, 2658-2860. [CrossRef]

10. Huang, S.Z.; Wu, K.Y. Health Risk Assessment of Photoresists Used in an Optoelectronic Semiconductor Factory. Risk Anal. 2019, 39, 2625-2639. [CrossRef] [PubMed]

11. Calvert, P. Inkjet printing for materials and devices. Chem. Mater. 2001, 13, 3299-3305. [CrossRef]

12. Theodorakos, I.; Zacharatos, F.; Geremia, R.; Karnakis, D.; Zergioti, I. Selective laser sintering of Ag nanoparticles ink for applications in flexible electronics. Appl. Surf. Sci. 2015, 336, 157-162. [CrossRef]

13. Wong, W.S.; Salleo, A. Flexible Electronics: Materials and Applications; Springer Science+Business Media, LLC: New York, NY, USA, 2009; ISBN 0387743634.

14. Ko, S.H.; Pan, H.; Grigoropoulos, C.P.; Luscombe, C.K.; Fréchet, J.M.J.; Poulikakos, D. All-inkjet-printed flexible electronics fabrication on a polymer substrate by low-temperature high-resolution selective laser sintering of metal nanoparticles. Nanotechnology 2007, 18, 345202. [CrossRef]

15. Ko, S.H.; Pan, H.; Grigoropoulos, C.P.; Luscombe, C.K.; Fráchet, J.M.J.; Poulikakos, D. Air stable high resolution organic transistors by selective laser sintering of ink-jet printed metal nanoparticles. Appl. Phys. Lett. 2007, 90, 141103. [CrossRef]

16. Noh, J.; Ha, J.; Kim, D. Femtosecond and nanosecond laser sintering of silver nanoparticles on a flexible substrate. Appl. Surf. Sci. 2020, 511, 145574. [CrossRef]

17. Zenou, M.; Ermak, O.; Saar, A.; Kotler, Z. Laser sintering of copper nanoparticles. J. Phys. D Appl. Phys. 2014, $47,025501$. [CrossRef]

18. Lee, B.; Kim, Y.; Yang, S.; Jeong, I.; Moon, J. A low-cure-temperature copper nano ink for highly conductive printed electrodes. Curr. Appl. Phys. 2009, 9, 157-160. [CrossRef]

19. Kim, T.Y.; Hwang, J.Y.; Moon, S.J. Laser curing of the silver/copper nanoparticle ink via optical property measurement and calculation. Jpn. J. Appl. Phys. 2010, 49, 05EA091-05EA096. [CrossRef]

20. Soltani, A.; Khorramdel Vahed, B.; Mardoukhi, A.; Mäntysalo, M. Laser sintering of copper nanoparticles on top of silicon substrates. Nanotechnology 2015, 27, 035203. [CrossRef] [PubMed]

21. German, R.M. German, Sintering theory and practice. Chapitre 1996, 12-13, 68-74.

22. Halonen, E.; Viiru, T.; Östman, K.; Cabezas, A.L.; Mantysalo, M. Oven sintering process optimization for inkjet-printed Ag Nanoparticle ink. IEEE Trans. Compon. Packag. Manuf. Technol. 2013, 3, 350-356. [CrossRef]

23. Perelaer, J.; De Gans, B.J.; Schubert, U.S. Ink-jet printing and microwave sintering of conductive silver tracks. Adv. Mater. 2006, 18, 2101-2104. [CrossRef]

24. Kim, D.; Moon, J. Highly Conductive Ink Jet Printed Films of Nanosilver Particles for Printable Electronics. Electrochem. Solid-State Lett. 2005, 8, J30-J33. [CrossRef]

25. Choi, J.H.; Ryu, K.; Park, K.; Moon, S.J. Thermal conductivity estimation of inkjet-printed silver nanoparticle ink during continuous wave laser sintering. Int. J. Heat Mass Transf. 2015, 85, 904-909. [CrossRef]

26. Bolduc, M.; Trudeau, C.; Beaupré, P.; Cloutier, S.G.; Galarneau, P. Thermal Dynamics Effects using Pulse-Shaping Laser Sintering of Printed Silver Inks. Sci. Rep. 2018, 8, 1418. [CrossRef] [PubMed]

27. Kim, M.; Jee, H.; Lee, J. Photo-Sintered Silver Thin Films by a High-Power UV-LED Module for Flexible Electronic Applications. Nanomaterials 2021, 11, 2840. [CrossRef]

28. Magdassi, S.; Grouchko, M.; Berezin, O.; Kamyshny, A. Triggering the sintering of silver nanoparticles at room temperature. ACS Nano 2010, 4, 1943-1948. [CrossRef]

29. Allen, M.L.; Aronniemi, M.; Mattila, T.; Alastalo, A.; Ojanperä, K.; Suhonen, M.; Seppä, H. Electrical sintering of nanoparticle structures. Nanotechnology 2008, 19, 175201. [CrossRef] [PubMed]

30. Moon, Y.J.; Lee, S.H.; Kang, H.; Kang, K.; Kim, K.Y.; Hwang, J.Y.; Cho, Y.J. Electrical sintering of inkjet-printed silver electrode for c-Si solar cells. PLoS ONE 2011, 6, e17209. [CrossRef] 
31. Alastalo, A.T.; Seppä, H.; Leppäniemi, J.H.; Aronniemi, M.J.; Allen, M.L.; Mattila, T. Modelling of nanoparticle sintering under electrical boundary conditions. J. Phys. D Appl. Phys. 2010, 43, 485501. [CrossRef]

32. Tan, H.W.; Saengchairat, N.; Goh, G.L.; An, J.; Chua, C.K.; Tran, T. Induction Sintering of Silver Nanoparticle Inks on Polyimide Substrates. Adv. Mater. Technol. 2020, 7, 1900897. [CrossRef]

33. Jang, S.; Lee, D.J.; Lee, D.; Oh, J.H. Electrical sintering characteristics of inkjet-printed conductive Ag lines on a paper substrate. Thin Solid Films 2013, 546, 157-161. [CrossRef]

34. Lee, H.; Kim, D.; Lee, I.; Moon, Y.J.; Hwang, J.Y.; Park, K.; Moon, S.J. Stepwise current electrical sintering method for inkjet-printed conductive ink. Jpn. J. Appl. Phys. 2014, 53, 05HC07. [CrossRef]

35. Moon, Y.J.; Kang, H.; Kang, K.; Moon, S.J.; Young hwang, J. Effect of Thickness on Surface Morphology of Silver Nanoparticle Layer During Furnace Sintering. J. Electron. Mater. 2015, 44, 1192-1199. [CrossRef]

36. Kittel, C. Introduction to Solid State Physics, 8th ed.; John Wiley \& Sons, Inc.: Hoboken, NJ, USA, $2005 ;$ ISBN 9783540938033.

37. Kim, D.; Lee, I.; Yoo, Y.; Moon, Y.J.; Moon, S.J. Transient variation of a cross-sectional area of inkjet-printed silver nanoparticle ink during furnace sintering. Appl. Surf. Sci. 2014, 305, 453-458. [CrossRef]

38. Wang, T.; Chen, X.; Lu, G.Q.; Lei, G.Y. Low-temperature sintering with nano-silver paste in die-attached interconnection. J. Electron. Mater. 2007, 36, 1333-1340. [CrossRef]

39. Greer, J.R.; Street, R.A. Thermal cure effects on electrical performance of nanoparticle silver inks. Acta Mater. 2007, 55, 6345-6349. [CrossRef]

40. Lee, D.G.; Kim, D.K.; Moon, Y.J.; Moon, S.J. Effect of temperature on electrical conductance of inkjet-printed silver nanoparticle ink during continuous wave laser sintering. Thin Solid Films 2013, 546, 443-447. [CrossRef]

41. Kusy, A.; Listkiewicz, E. Percolation network for thick resistive films. Solid. State. Electron. 1988, 31, 821-830. [CrossRef] 